five months, and three of the men who managed to maintain their weights better than the others also maintained their serum choline esterases much better. It is not thought that these increases in choline esterase were due to the digestion, absorption and metabolism of fat setting free non-specific esterases into the serum, for when six men were given a supplement of $100 \mathrm{gm}$. of fat daily for three days there was no increase in the 'total' choline esterase found in their sera.

These results, and others which have not yet been published, suggest that the average level of the 'pseudo' enzyme in the serum is a delicate index of the state of nutrition of any group of men in Germany to-day.

It is hoped to publish the results of this work in full in the near future, and various aspects of it are being actively studied at the moment; but we think it may be helpful to those working on the enzymes to know at this stage that we have obtained these results. The knowledge may possibly assist them to establish the relationship of the enzymes to the liver and to the other organs involved in their functional activity.

\section{R. A. MCCANCE}

E. M. WIDDOWSON

A. O. Hutchinson

Department of Experimental Medicine,

University of Cambridge, and

Wuppertal, B.A.O.R. Nov. 4.

${ }^{1}$ McArdle, B., Quart. J. Med., N.S., 9. 107 (1940).

'Mendel, B., Mundell, D. B., and Rudney, H., Biochem. J., 37, 473 (1943).

\section{Premortal Increase in the Output of Sodium and Chlorine in Fasting Rats}

KUNSTMANN, in an experiment on himself ${ }^{1}$, drank 10-20 litres of water daily, with an otherwise normal food intake. He felt fit during the experiment, his urinary output in sodium and chlorine sank to minimal values; but nevertheless his sodium chloride balance became negative. On about the thirtieth day of the experiment, his chlorine excretion rose to abnormally high values and he felt ill, so he ended the experiment. We attempted to reproduce this experiment with rats. We gave them maize washed out in water, and twice daily $10 \mathrm{ml}$. of a 5.5 per cent glucose solution subcutaneously. In this way we attained great quantities of a rather dilute urine; the animals slowly lost weight; but the output of sodium and chlorine showed no increase, even on the fiftieth day of the experiment, and we failed to obtain a negative salt balance.

We decided, therefore, to make the rats fast, without or with water ad libitum, with twice daily $10 \mathrm{ml}$. of a 5.5 per cent glucose solution subcutaneously; we collected urine specimens daily and analysed them for sodium, potassium, chlorine and nitrogen. In all cases, on the last day before death, the output of sodium and chlorine was three to six times as great as on the previous days. We varied our experiments by giving the rats free access to water, but no extra injections. In about half the cases we observed the same phenomenon: the last day's sodium and chlorine output was many times greater than on the previous days. With 2 per cent urea solution ( $10 \mathrm{mI}$. twice daily subcutaneously) we obtained the same result.

In some cases we succeeded in keeping the animals alive after the end of the experiment by giving them adequate food, so this phenomenon cannot be regarded as absolutely fatal. The fasting animals lived from four to nine days, and there seems to be no correlation between the duration of the experiment and the appearance of the increased sodium chloride output. No correlation was found between increased output of sodium chloride on one hand and sex, weight, room temperature, water intake, quantity of urine and nitrogen output of the rats on the other.

We have insufficient evidence to suggest the mech. anism and cause of this increased output. We calculated according to Gamble, Ross and Tisdall's procedure $^{2}$ the loss of weight from the excreted amount of potassium, sodium and nitrogen and compared the data with the measured loss of weight. In most cases showing the increased sodium chloride output, the calculated loss exceeded the measured loss and this, with high serum sodium values, would suggest that the organism had some reserves of sodium chloride in 'dry' form, which are excreted after prolonged fasting. In other cases we found normal and even subnormal serum sodium levels as well. We realize that the existence or non-existence of 'dry' sodium chloride reserves is still a much discussed. problem of physiology, and the evidence given above is not enough to give a positive answer. Further work on the mechanism involved is in progress.

Peter Balint

Medical Clinic,

University, Pécs.

HeLENe KabDebó Sept. 8.

'Kunstmann, L., Arch. exper. Path. Pharmak., 170, 701 (1933).

${ }^{2}$ Gamble, J. L., Ross, G. S., and Tisdall, F. F., J. Biol. Chem., 57, 633 (1923).

\section{Thyroid Gland as a Special Factor Influencing the Conditional Disposition to Infectious Diseases}

There are several old and recent observations concerning the important effect of the ductless glands on disposition against infections and infectious diseases. From this point of view the role of the thyroid should especially be emphasized.

Some authors ${ }^{1}$ suggest a specific role (specific bacteriostatic action) of thyroxine; but the maj. ority $^{2-7}$ assume a non-specific effect on the defence mechanism of the organism.

It is more correct to speak of conditions rather than causes producing diseases, regarding the constitution not as a static but as a dynamic unity. I reported in $1938^{8}$ on my investigations with Reid-Hunt's method. They favour the assumption that alterations in the quantity of thyroxine in the blood are closely related to infections. My further investigations with Euler's method ${ }^{9}$ pointed to the marked increase of the thyroxine-level in serum during infectious diseases (smallpox vaccination). It seemed that this increase was parallel with the reaction of the body to the infection and closely related to the development and stimulation of the defence mechanism. I found at the same time ${ }^{10}$ that the patients displaying a higher thyroxine-level were rather free from the complications due to secondary infection in scarlet fever.

Starting from these observations, I administered daily to 283 patients ${ }^{11}$ suffering from scarlet fever $50 \mathrm{cgm}$. of fresh thyroid powder from their entry to hospital until their discharge. The experiments were carried out during one season, the patients came 